\title{
SINGLE SESSION WORK: INTERVENÇÃO ÚNICA COM A FAMÍLIA E ADOLESCENTE EM CONFLITO COMALEI
}

\section{SINGLE SESSION WORK: SINGLE INTERVENTION WITH THE FAMILY AND ADOLESCENT IN CONFLICT WITH THE LAW}

\author{
Liana Fortunato Costa* \\ Flávio Lôbo Guimarães ** \\ Luciana Monteiro Pessina*** \\ Maria Fátima Olivier Sudbrack****
}

\begin{abstract}
Costa LF, Guimarães FL, Pessina LM, Sudbrack MFO. Single session work: intervenção única com a família e adolescente em conflito com a lei. Rev Bras Crescimento Desenvolv Hum. 2007; 17(3): 104-113.
\end{abstract}

\begin{abstract}
Resumo: Neste trabalho apresentamos e discutimos uma metodologia de avaliação familiar numa perspectiva da Single Session Work, que é baseada numa única intervenção, e se destina ao atendimento de adolescente em conflito com a lei. A avaliação familiar compreendeu os seguintes objetivos: levantar informações psicossociais que possibilitassem uma melhor compreensão das características da clientela atendida; compreender o paradigma familiar, identificando os elementos relacionados à eclosão da crise atual, entendendo por crise o envolvimento do adolescente com a Justiça; estimular as famílias a estabelecerem novos paradigmas, capazes de responder à crise. Acreditamos que esta metodologia pode ser útil no contexto judiciário, com essa população de adolescentes, que cumpre medidas socieducativas e que não apresenta demanda para transformações. Reconhecemos seu potencial de gerar informação, resgatar vínculos parentais, significar o ato delinqüente, por ser uma intervenção crítica pontual e que reativa as potencialidades e a criatividade tanto da família quanto da equipe técnica.
\end{abstract}

Palavras-chave: Medida socioeducativa. Adolescente em conflito com a lei. Avaliação familiar. Psicologia jurídica. Single session work.

Este trabalho tem por objetivo apresentar e discutir uma metodologia de avaliação familiar desenvolvida no âmbito do Projeto Fênix (Atendimento Psicossocial a Adolescentes em Medida Socioeducativa) ${ }^{1}$. Esse projeto resultou de um convênio entre a Vara da Infância e da Ju- ventude do Distrito Federal - Brasil (VIJ/DF), a Secretaria de Estado de Ação Social (SEAS/ DF) e a Universidade de Brasília (UnB), através de dois programas - Programa de Estudos e Atenção às Dependências Químicas (PRODEQUI) e Programa de Atendimento ao Alcoolis-

\footnotetext{
* Psicóloga, Terapeuta Conjugal e Familiar, Psicodramatista. Doutora em Psicologia Clínica pela Universidade de São Paulo. Docente Permanente do Departamento de Psicologia Clínica da Universidade de Brasília. Professora Supervisora do Projeto Fênix. SQN 104 Bloco D ap. 307 Brasília - DF - 70.733 040 Tel: 613328 - 7439 Fax: 6133269710 E-mail: lianaf@terra.com.br

** Psicólogo, Terapeuta Conjugal e Familiar Mestre em Psicologia pela Universidade de Brasília, Supervisor de Estágio em Psicologia Jurídica da Universidade Paulista - UNIP/ DF. Membro Integrante do Projeto Fênix

E-mail: flaviopsi@yahoo.com.br

*** Psicóloga, Terapeuta Conjugal e Familiar em Formação. Membro Integrante do Projeto Fênix E-mail:lpessina@terra.com.br

**** Psicóloga, Terapeuta Conjugal e Familiar, Docteur en Psychologie pela Université Paris XIII, Professora Titular do Departamento de Psicologia Clínica da Universidade de Brasília, Pesquisadora do CNPq - Conselho Nacional de Pesquisa. Coordenadora do Projeto Fênix. E-mail: fatsudbr@unb.br
} 
mo (PAA).

Nossa proposta de metodologia se centra no conceito de SSW (Single Session Work), que é uma forma de oferecer atendimento em maior escala à comunidade, garantindo confiabilidade a este atendimento. Esta forma diz respeito a um único atendimento, que é realizado de forma intensa, potente, focal, sem compromisso com outros atendimentos e com o máximo de investimento técnico, pessoal ou metodológico, por parte dos profissionais. Vários são os autores que estão investindo nesta forma de trabalhar: Moshe Talmon em Israel, Robert Rosenbaun e Jeff Young nos Estados Unidos. Na Austrália, o The Bouverie Centre - Victoria's Family Institute (bouverie.centre@latrobe.edu.au) utiliza este conceito para atendimento e formação de psicólogos familiares, a partir do conceito de solution focus, presente na Terapia Narrativa de Michel White $^{2}$. Também encontramos muitos trabalhos publicados, nesta perspectiva, na revista americana da área de serviço social, Social Work With Groups. Omer ${ }^{3}$, terapeuta familiar israelense que tem grande penetração na comunidade brasileira de terapia familiar, propõe um atendimento que é caracterizado pela "presença ativa dos pais" e que segue esta orientação.

O Projeto Fênix teve como marco jurídico a Constituição Federal, que, em seu artigo 227, estabelece a doutrina da proteção integral a crianças e adolescentes como um dever do Estado, da sociedade e da família. O Estatuto da Criança e do Adolescente regulamenta o artigo 227 e prevê medidas de proteção aplicáveis a crianças e adolescentes. Dentre outras medidas, aquelas previstas no artigo 101, incisos V e VI do ECA foram objeto de trabalho do Projeto Fênix. O inciso $\mathrm{V}$ prevê a "requisição de tratamento médico, psicológico ou psiquiátrico, em regime hospitalar ou ambulatorial"; o inciso VI prevê a "inclusão em programa oficial ou comunitário de auxílio, orientação e tratamento a alcoólatras e toxicômanos".

O projeto destinou-se a prover atendimento psicossocial a 100 adolescentes usuários de drogas encaminhados pela VIJ e suas famílias, com o duplo objetivo de produzir conhecimentos e implantar uma nova proposta de intervenção psi- cossocial e abordagem da drogadição. Para isso, desenvolveram-se várias modalidades de atividades, como grupos multifamiliares, avaliações familiares, consultas médicas, avaliações psicopedagógicas, grupos de pais, oficinas de idéias e atendimentos grupais e individuais para adolescentes e seus familiares, planejadas e conduzidas por uma equipe multidisciplinar de psicólogos, assistentes sociais, médicos, enfermeiros e pedagogos.

Todos os adolescentes que integraram o projeto estavam cumprindo medida socieducativa, alguns em mais de uma medida, outros com várias entradas no sistema prisional. Quase todas as famílias (em torno de $80 \%$ ) eram provenientes da periferia, com baixa renda familiar, e foram intimadas a comparecerem aos atendimentos por imposição judicial.

\section{Enfoque teórico}

A perspectiva sistêmica constitui um importante recurso para a compreensão do comportamento humano, e uma de suas principais características é a ampliação do foco de análise. A partir dessa perspectiva, a conduta de um adolescente reflete mais que suas características de personalidade, seus anseios e conflitos pessoais. O comportamento de um indivíduo é concebido como parte de um jogo relacional complexo, composto por vários outros indivíduos, contextos e regras de conduta. Em nosso projeto, abordamos todos esses contextos em diferentes momentos e atividades. A avaliação familiar procurou se deter sobre as questões referentes ao sistema familiar de cada adolescente.

Segundo Minuchin ${ }^{4}$, a família é um sistema aberto em transformação, isto é, constantemente recebe e envia inputs do meio extrafamiliar, e se adapta às diferentes exigências dos estádios de desenvolvimento que enfrenta. A visão sistêmica da família proposta por esse autor procura identificar a estrutura familiar, seus padrões de relacionamento mais recorrentes, a hierarquia, as relações de poder, os vínculos e alianças, a distribuição de papéis, os padrões de comunicação, entre outros aspectos.

Nosso enfoque no atendimento a adoles- 
centes segue uma orientação teórica sistêmica que compreende que, nessa faixa etária, existe uma grande dependência ainda entre o adolescente e o grupo familiar. Fishman ${ }^{5}$ propõe que a abordagem aos problemas dos adolescentes seja feita inicialmente a partir da família, porque as questões de identidade e separação em relação aos pais estão extremamente sensíveis.

Outro terapeuta de família, Stanton ${ }^{6}$, também concorda que o atendimento prestado a essa população seja realizado preferencialmente com a família, já que o período da adolescência traz grandes impasses que envolvem a família, como os processos de individualização e de individuação. A individualização é o processo de busca de sua própria identidade, e tem curso na intimidade do adolescente. Já o processo de individuação ocorre com a separação emocional que o adolescente faz em relação a figuras de maior influência sobre ele até então, que são seus pais.

Enfim, consideramos a família como um todo relacional inserida sempre em um contexto social mais amplo, mas também contendo subsistemas nos quais o adolescente integra uns e está fora de outros ${ }^{7}$.

Buscamos ainda complementar nossa abordagem dando ênfase especial às contribuições do Construtivismo e do Construcionismo Social. Ambas correntes teóricas privilegiam o aspecto construtivo das relações estabelecidas no presente como novas influências com competência para fazer frente a outras relações já vividas. O pensamento construcionista pôs o foco na linguagem, acreditando que um significado é produzido em uma relação dialógica. Houve a ampliação da noção de sistema, passando-se a falar em sistemas significantes, que são os sistemas que falam ou conversam sobre algo. No nosso caso trabalhamos com aquele sistema que tem algo a dizer sobre aquele adolescente ${ }^{8}$.

Em especial procuramos dirigir nossas intervenções para a construção de novas narrativas acerca do adolescente e dos problemas que são trazidos e que o envolvem ${ }^{9}$, e desse modo assumimos a postura de Vasconcellos ${ }^{10}$ que considera que todo terapeuta sistêmico é necessariamente um terapeuta construtivista/construcionista/narrativista.
A perspectiva sistêmica constitui um importante recurso para a compreensão do comportamento humano, e uma de suas principais características é a ampliação do foco de análise. Nessa perspectiva, a conduta de um adolescente reflete mais que suas características de personalidade, seus anseios e conflitos pessoais. $\mathrm{O}$ comportamento de um indivíduo é concebido como parte de um jogo relacional complexo, composto por vários outros indivíduos, contextos e regras de conduta ${ }^{11}$.

Um adolescente que apresenta um comportamento delinqüente pode estar reagindo a algum dos aspectos apontados e pode estar denunciando alguma necessidade de mudança. Nesse sentido, a perspectiva sistêmica concebe o comportamento desviante de um adolescente como um sintoma, que possui uma função dentro do sistema familiar ${ }^{6,12,13}$ Sudbrack, 1992.

Para Ausloos ${ }^{14}$, o sintoma pode ser visto como uma tentativa do sistema mostrar uma mudança sem que, de fato, nenhuma mudança ocorra, é um sinal de advertência de que não há soluções nas modalidades habituais de interação que o sistema apresenta. É preciso que algo novo se produza.

Nesse sentido, torna-se fundamental avaliar o contexto relacional de um adolescente para melhor compreendê-lo. A família, o grupo de pares e a escola constituem os principais sistemas em que o adolescente está inserido. Em relação a nossa clientela, não podemos nos esquecer do mundo do tráfico como um sistema bastante presente na vida dos adolescentes. Em nosso projeto, abordamos todos esses contextos em diferentes momentos e atividades. A avaliação familiar enfocou o sistema familiar de cada adolescente.

\section{Drogas e delitos}

A questão das drogas tem adquirido proporções que desafiam visões simplificadoras e maniqueístas. Segundo Olivenstein ${ }^{15}$ o consumo de drogas se dá em três dimensões, e devem ser considerados três aspectos em conjunto: o encontro de um produto, de uma personalidade e de um momento sociocultural. Sudbrack ${ }^{16}$ enfa- 
tiza quer a delinquiência não pode ser reduzida nem a um controle social, nem somente à instância jurídica, pois a questão remete a uma implicação particular entre o delinqüiente e seu ambiente social e familiar.

Penso $^{17}$ (2003), ao estudar a construção identitária de adolescentes com envolvimento em atos infracionais e com drogas, descreveu as dinâmicas familiares e as dificuldades desses adolescentes nos processos de separação e pertencimento, que envolvem esse contexto.

Nossa experiência em clínica de adolescentes e famílias mostra o quanto esses autores citados apontam aspectos que nós observamos nos atendimentos. Por isso, nesse projeto privilegiamos, a despeito das grandes dificuldades de comparecimento, o enfoque na família. Em sua maioria, residentes das cidades de periferia de Brasília e com situações de desemprego dos pais, as famílias tinham dificuldades de se deslocarem constantemente aos locais do projeto. Assim, a avaliação familiar teve como premissa a necessidade de aproveitar intensamente a presença da família, transformando esses impasses em estratégias.

\section{Single session work: a avaliação familiar}

Dentre as atividades desenvolvidas, a avaliação familiar compreendeu os seguintes objetivos:

- levantar informações psicossociais que possibilitassem uma melhor compreensão das características da clientela atendida;

- compreender o paradigma familiar, identificando os elementos relacionados à eclosão da crise atual, entendendo por crise o envolvimento do adolescente com a Justiça;

- estimular as famílias a estabelecerem novos paradigmas, capazes de responder à crise.

Tomamos como base o conceito de paradigma familiar de Schnitman e Fuks ${ }^{18}$ : a crença que a família tem sobre seu funcionamento é que permite que ela resolva suas questões. De outro modo podemos dizer que a família tem um modus operandi de resolução de seus conflitos, e acredita que fazendo daquele jeito dá certo. $\mathrm{O}$ paradigma é aprendido com as formulações de solução de conflitos que uma geração aprende com a anterior, também com os aspectos culturais, históricos, sociais e econômicos que os rodeiam. Esse paradigma familiar tem "prazo de validade/vencimento", ou seja ele tem uma utilidade que é histórica, servindo por um determinado tempo da dinâmica familiar.

O Ciclo de Vida familiar é importante para entender o vencimento do prazo de validade do paradigma. A crença no poder de solução permanece enquanto o paradigma está em vigência. Sendo assim a família sabe como proceder diante de problemas ${ }^{19}$. A entrada dos filhos na adolescência representa, invariavelmente, uma quebra desse paradigma nesse momento histórico da família.

$\mathrm{Na}$ clínica da drogadição, encontramos uma ausência imensa de demanda por tratamentos. Uma visão sistêmica da demanda ${ }^{20}$ nos permite analisá-la em termos de seus elementos: sintoma, sofrimento e o pedido. Quando encontramos esses elementos em um mesmo indivíduo, temos uma demanda devidamente formulada. No nosso caso, na falta de demanda devidamente formulada, os elementos da demanda encontram-se dispersos: o adolescente apresenta um sintoma (a droga), a mãe sofre imensamente (é nervosa) e o pai faz o pedido (entrega o filho para o juiz). No contexto do uso abusivo de drogas associado ao contexto da justiça, o adolescente segue com o sintoma, não acredita estar errado ou que precisa de ajuda; todos da família sofrem, principalmente sua mãe. Apesar de sofrerem, estes últimos, por vezes, não chegam a formular um pedido de ajuda ou não encontram espaços em que possam fazê-lo. E é o juiz quem formula o pedido de ajuda, encaminhando a família para os psicólogos e assistentes sociais do projeto.

\section{Construção de sentidos para a medida socie- ducativa}

Além do enfoque sistêmico que delineia o universo relacional no qual o adolescente em conflito com a lei está inserido, procuramos explorar os sistemas de significados construídos pela família acerca de sua situação. Assim, alterna- 
mos uma visão funcionalista dos sistemas humanos com uma perspectiva que propõe que "a vida das pessoas é modelada pela significação que elas atribuem a sua experiência, pela situação que ocupam nas estruturas sociais e pelas práticas culturais e da linguagem do eu e de suas relações"2 (p.30).

Estamos nos referindo ao caráter social da linguagem, explicitado na estreita relação entre sentidos compartilhados e os padrões sociais. Dessa forma, "apreciar as formas existentes de discurso é avaliar os padrões de vida cultural" $^{21}$ (p. 161).

A partir do esgotamento do paradigma familiar de soluções, o sistema gera uma descrença quanto a ele mesmo poder resolver os problemas. Desse modo, instala-se a crise familiar. Diante da crise os membros da família não sabem ou não conseguem agir, facilitando que o adolescente expresse uma passagem ao ato (acting out) que, na maioria das vezes, ultrapassa as fronteiras do círculo familiar e se expressa no contexto social ${ }^{22}$. Sendo assim, o meio social se apresenta para ajudar a família a estabelecer um novo paradigma através da medida socieducativa.

A proposta de avaliação familiar surge nesse momento, estabelecendo um atendimento realizado de forma pontual, estratégica e provocativa $^{6}$, privilegiando o resgate da autoridade "paterna" e enfocando a grande fusão emocional existente entre o filho e a mãe.

A meta é estabelecer um novo paradigma familiar, restabelecendo assim uma outra crença, diferente da anterior, sobre a resolução dos problemas. A intervenção busca evidenciar que a questão, que está ocorrendo e que traz preocupações, está mais ligada à falência daquele paradigma.

Rígido ou flexível, limitado ou abrangente, o paradigma familiar é acolhido pela equipe de terapeutas, pois “(...) não temos de pedir à família que mude a sua epistemologia. Pelo contrário, é aceitando a sua que podemos ter uma oportunidade de os levar a partilhar a nossa" ${ }^{23}$ (p. 35). Nesse sentido, procuramos promover um contexto que acolha diferentes versões e opiniões acerca de uma mesma questão, deixando clara a nossa opção pela multiplicidade. Acreditamos que é justamente esse contex to o incentivador da mudança de significados.

$\mathrm{Omer}^{24}$, terapeuta familiar que trabalha com adolescentes em situações de crise máxima, propõe uma intervenção que seja única, potente, calcada numa retomada da autoridade paterna, ou de um membro masculino da família, para o restabelecimento imediato de um contexto protetor para o adolescente. Em função das grandes dificuldades da presença paterna junto ao adolescente, nesse contexto de famílias com baixa renda, introduzimos a possibilidade da intervenção se ampliar e podermos contar com a presença de figuras masculinas importantes para o adolescente, como um parente, um amigo, um professor. Essa perspectiva se ampara no conceito de rede social ${ }^{25}$.

A atuação dos profissionais que atendem a família é fundamental na reconstrução desses sentidos, não só para a aplicação da medida socioeducativa, como também para a recolocação dos papéis parentais e da autoridade. Buscam a requalicar a competência familiar ${ }^{23}$ quando reconhecem um axioma que é a base da intervenção para esse autor: toda família só se coloca um problema que seja capaz de resolver. Trabalham ativamente no processo de construção da demanda, que tem início nessa primeira intervenção, com o objetivo de o mais rápido possível configurá-la, para que esse processo seja concluído até o final da aplicação da medida. Atuam como mediadores possibilitando a comunicação verbal e afetiva entre os membros da família, pois compreendemos que, até o momento, suas comunicações têm sido feitas através de atuações ${ }^{2}$.

\section{A metodologia da avaliação familiar}

Nossa proposta de atendimento à família é realizada por uma equipe terapêutica, na qual dois integrantes da equipe ficam diretamente com a família, e os demais (outros integrantes, observadores) ficam um pouco mais afastados, no sentido de poderem observar, com maior pertinência e de forma mais ampla, os aspectos que escapem àqueles que estão diretamente com a 
família ${ }^{26}$.

A sessão de avaliação familiar estruturouse segundo as etapas abaixo descritas:

- Contextualização: Com duração aproximada de 10 minutos, esta etapa consiste em apresentar a equipe e o contexto do atendimento e seus objetivos, propiciar um espaço de conversação para cada família, visando a circulação de informação e a produção de conhecimento sobre eles mesmos ${ }^{8,23,27}$.

- Identificação da família: Durante cerca de 15 minutos, a família responde oralmente a um questionário, com o objetivo de conhecer os indicadores psicossociais da família.

- Apresentação da família: Com a utilização da técnica do questionamento circular ${ }^{8}$ durante aproximadamente 20 minutos, busca-se nesta etapa uma leitura sistêmica da família (funcionamento, papéis, fronteiras, subsistemas, alianças, poder, regras, comunicação).

- Compreensão da função do sintoma: Neste momento, procura-se junto com a família recompor a relação entre a crise familiar e a medida socioeducativa, através de perguntas como: "Como a família compreende o que está acontecendo?". Enquanto a família expõe suas explicações para o presente, a equipe faz perguntas sobre o passado que possibilitem compor uma história da família ligada ao ato infracional e assim compreender os sentidos construídos pela família acerca da crise. Esta etapa tem a duração média de 20 minutos.

- Intervalo/elaboração da carta: Nesta etapa, que dura entre 15 e 20 minutos, a equipe deixa a família para reunir-se em outra sala e discutir o atendimento. As diferentes interpretações dos membros da equipe são expostas e elabora-se uma breve carta à família, oferecendo uma ressignificação da passagem ao ato. Os elementos fundamentais da carta ${ }^{28}$ são: a conotação positiva do sintoma ${ }^{8}$, ou seja, como o sintoma estava ajudando a família; as contradições e sofrimentos decorrentes do sintoma, isto é, seus "efeitos colaterais" indesejados; e a provocação para a mudança, feita através de perguntas sobre como a família resolveria as contradições. A carta é redigida à mão, e entregue, em seguida, para a família.
- Leitura/entrega da carta: Ao reencontrar-se com a família, a equipe faz uma leitura solene, em voz alta, da carta, explicando antes que não haverá espaço para comentários por parte da família. Em seguida, entrega-se a carta à família. Adotamos essa indicação de não discutir a carta para que a família saia do encontro sob o impacto provocativo da carta.

- Prescrição da tarefa: A equipe, então, solicita à família que se reúna em casa e converse sobre a carta, respondendo às questões apontadas, e que também procurem formular um pedido da família a ser levado à Justiça na próxima audiência com o juiz.

\section{Exemplificando}

\section{A Família que chora unida permanece unida}

A família compareceu representada pelo adolescente Jéferson, 17 anos, e seu irmão, por parte de mãe, Daniel, 26 anos. A família era proveniente de uma cidade do interior de outro estado. Jéferson havia sido preso dois meses antes da sessão sob a acusação de tráfico de drogas, tendo sido filmado pelas câmeras de um posto de gasolina.

O pai de Jéferson havia morrido 6 meses antes, de câncer, de modo rápido e inesperado. A família ainda estava muito triste e conversava pouco sobre essa tristeza. Francisco, irmão de 19 anos (não esteve presente na sessão), era a pessoa mais próxima de Jéferson e foi descrito por Daniel como tendo "quase o mesmo problema que ele". Não parecia haver clima e condições para que o adolescente conversasse com sua mãe ou com Daniel. Durante a sessão, Jéferson ficou mais calado, aceitando Daniel como porta-voz da família.

\section{Compreensão da função do sintoma}

Daniel nos trouxe sua explicação do que estava acontecendo com Jéferson. No seu tempo de jovem, as coisas eram diferentes, ele tinha que arrumar a cama, não podia deixar a toalha enrolada, não podia ficar na rua. A forma de seu padrasto e sua mãe agirem com os irmãos mais 
novos não era a mesma: Jéferson e Francisco tinham mais liberdade, fazendo "o que dava na telha" sem serem cobrados. Foram deixando de ir para a escola, começaram a fumar cigarro, até chegarem a usar entorpecentes e dormir fora de casa. Para Daniel, uma sucessão de pequenas coisas culminou na situação em que se encontravam então. Mas ainda achava que Jéferson teria a chance de corrigir o seu erro, através da Justiça, da prestação de serviços comunitários e da inserção no projeto Fênix. Daniel reconhecia, no entanto, que Jéferson estava um pouco sozinho, já que tinha dificuldade de relacionar-se com ele mesmo e tinha conflitos com a mãe autoritária, enquanto Francisco, embora próximo, andava muito mais ocupado com sua namorada. Enquanto Daniel falava, Jéferson olhava-o e escutava-o atentamente. Isso foi apontado pela equipe como um reconhecimento de Jéferson da autoridade de Daniel para falar por ele.

Através da técnica do presente-ausente, um membro da equipe colocou-se no lugar da mãe, falando da coincidência de Jéferson ter sido preso exatamente no dia em que a morte do pai completava quatro meses. Este se emocionou e Daniel começou a chorar bastante.

Essa técnica consiste em solicitar à família que indique onde os membros ausentes se sentariam caso estivessem presentes. Ao longo da sessão, pode-se perguntar o que esses membros diriam, sentiriam ou pensariam se estivessem participando da conversa. Colocamos o membro ausente "como se" estivesse presente $^{29}$. Pode-se, ainda, fazer um duplo dos membros ausentes. O duplo é uma técnica do Psicodrama que consiste em dar voz a um sentimento que está sendo comunicado de forma apenas implícita, ou a algo que poderia ser comunicado, mas não está claro $^{30}$.

A equipe ressaltou o fato de que Jéferson e Daniel estavam muito próximos no choro e na dor. Ressaltou ainda a importância do pai e da mãe nesta família como figuras fortes de referência de valor, trabalho e integridade. Esta última havia sido descrita por Daniel como estando muito debilitada pela morte do pai, e impossibilitada de tomar conta de Jéferson naquele momento.
Intervalo. Hipóteses da equipe quanto à função do sintoma.

Em discussão, no intervalo, a equipe reuniu algumas observações e impressões:

- Daniel está na dúvida se deve ou não assumir o papel de pai de Jéferson.

- Daniel conseguiu vencer na vida através da racionalidade e trabalho árduo, mas agora está chorando muito a morte do padrasto, expressando uma sensibilidade afetivoemocional.

-Jéferson está protegendo sua mãe através de seu comportamento de risco, pois assim ela terá que sair de sua tristeza e de seu choro constante, e dar atenção aos fatos em andamento.

- A família está muito só. Cada indivíduo está isolado, sem intimidade com os demais. $\mathrm{Na}$ cidade de origem, era mais fácil administrar a vida dessa forma. Na cidade grande, a família se dispersa porque é distante em termos de intimidade. $\mathrm{O}$ controle foi perdido. Aquele "tomar conta", do pai e da mãe, se afrouxou.

- Se fossemos dar um título para essa família seria: "Cada um na sua", pois estão ligados e juntos no sentimento, mas sem intimidade para compartilhar sua dor pela perda do pai: Daniel trabalha 12 horas por dia, a mãe chora trancada dentro de casa, Francisco se esconde na casa da namorada e Jéferson fuma, cheira e trafica.

- A crise é uma oportunidade para que todos fiquem "numa só" (ao invés de "cada um na sua”), pela união nas situações de exceção.

\section{Elaboração da carta}

A carta para a família está transcrita abaixo:

Jéferson, Daniel, $D^{a}$ Lucia e Francisco

A gente tem que agradecer a esta família por ter vindo com tão boa vontade em tempos tão difíceis, querendo acreditar em nós e na Justiça, mesmo vivendo ainda momentos tão dolorosos. Agradecemos à $D^{a}$ Lucia não ter vindo hoje, para a gente poder conhecer a força do Daniel. Agradecemos ao Francisco não ter vindo, para a gente poder compreender o quanto o Daniel e o Jéferson são 
importantes um para o outro. Agradecemos ao Daniel ter negociado com seu chefe para poder vir hoje aqui, para que nós pudéssemos conhecer a dedicação que ele pode ter em relação ao Jéferson. Agradecemos ao Jéferson por ter vindo para nos contar que ele precisava ser filmado como ator principal de um filme e que esse filme ainda precisa ser melhor compreendido.

Essa família nos lembra um título: "Família Cada Um na Sua”. Essa família consegue manter todo o mundo junto no sofrimento e na dor, mas no dia-a-dia parece que prevalece o "cada um na sua". No entanto, já há nessa família uma compreensão do momento que está sendo vivido, que é a possibilidade de sair do "cada um na sua" para "todos numa só”. O Jéferson está dando uma "dica” de como podem entrar "todos numa só", que é prestando atenção ao que o Daniel fala. $O$ Daniel já está dando outra dica de como podem entrar "todos numa só", que é aproveitar a oportunidade de todos buscarem, juntos, compreender a medida socioeducativa.

Como $D^{a}$ Lucia e Francisco podem contribuir para entrarem "todos numa só"? Como poderão entrar "todos numa só" no dia-adia da vida, sem precisar correr riscos, se envolvendo com drogas e delitos?

A equipe

\section{Discutindo a proposta}

A adoção desse modelo revelou-se eficaz em proporcionar uma compreensão sistêmica da família em apenas uma sessão. $O$ fato de o atendimento ser feito em equipe permitiu coletar impressões, interpretações e observações diversificadas a partir da experiência que os técnicos tiveram com a família. Essas informações eram tomadas não dentro de uma perspectiva exclusiva, do tipo ou isso ou aquilo, mas numa perspectiva inclusiva do tipo isso e aquilo, de modo a permitir a convivência de visões opostas e até mesmo contraditórias entre si, mas que eram consideradas úteis para compreender a família, sua história e seu contexto de vida ${ }^{31}$.

Essa metodologia proporcionou à equipe produzir um documento-síntese de cada avaliação familiar, contendo os fatores de risco e os fatores de proteção ao adolescente, presentes na família e no contexto imediato (escola, vizinhança). A preocupação não foi somente alertar para os riscos, mas sublinhar os recursos de que dispunham o adolescente e sua família para solucionar a crise ${ }^{23}$. O documento procurava evidenciar formas pelas quais a medida de proteção poderia potencializar esses recursos. $\mathrm{O}$ documento foi usado como referência por juízes e promotores durante as audiências/oitivas, que contavam com a participação de um dos profissionais presentes na avaliação familiar.

Após a intervenção, algumas famílias iniciaram transformações em seus paradigmas, possibilitando novas formas de lidar com os problemas protagonizados pelo adolescente.

\section{CONSIDERAÇÕES FINAIS}

Acreditamos que esta metodologia pode ser útil no contex to judiciário, com essa população de adolescentes, que cumpre medidas socieducativas e que não apresenta demanda para transformações. Reconhecemos seu potencial de gerar informação, resgatar vínculos parentais, significar o ato delinqüente, por ser uma intervenção crítica pontual e que reativa as potencialidades e a criatividade tanto da família quanto da equipe técnica.

Se, de um lado, o potencial deste modelo em sua dimensão avaliativa foi constatado, fazse necessário investigar com mais profundidade seu potencial interventivo, no sentido de ajudar as famílias a estabelecerem mudanças em seus paradigmas, possibilitando novas respostas à crise.

\footnotetext{
Abstract: This article aims at presenting and discussing a methodology for family evaluation in a perspective of the Single Session Work which is based on a single intervention and is destined to attend the adolescent in conflict with the law. Family evaluation comprised the following objectives: to raise psychosocial information that could enable a better understanding of the
} 
characteristics of the clientele; to understand the family paradigm, identifying the elements related to the emergence of the present crisis, understanding by crisis the involvement of the adolescent with Justice; to encourage the families to establish new paradigms, capable of responding to the crisis. We believe that this methodology can be useful in the judicial context with this population of adolescents who are under socioeducative measures and do not present demands for change. We recognize the method's potential to generate information, to rescue parental bonds and to signify the delinquent act, once it is a punctual critical intervention which reactivates the potentialities and the creativity both of the family and of the technical team.

Keywords: Socioeducative measure. Adolescent in conflict with the law. Family evaluation. Juridical psychology. Single session work.

\section{REFERENCIAS}

1. Sudbrack MFO, Conceição MIG, Seidl EMF, Silva MT. Adolescentes e drogas no contexto da Justiça. Brasília: Plano; 2003.

2. White M. Guias para una terapia familiar sistemica. Buenos Aires: Gedisa; 1997.

3. Omer H. Autoridade sem violência. O resgate da voz dos pais. Belo Horizonte: ArteSã; 2002.

4. Minuchin S. Famílias: funcionamento e tratamento. Porto Alegre: Artes Médicas; 1990.

5. Fishman HC. Tratamiento de adolescentes con problemas. Um enfoque de terapia familiar. Buenos Aires: Paidós; 1989.

6. Stanton MD, Todd F. Terapia familiar del abuso y adiccion a las drogas. Buenos Aires: Paidós; 1988.

7. Vasconcellos MJE. Pensamento sistêmico. O novo paradigma da ciência. São Paulo: Papirus/ UFMG; 2002.

8. Boscolo L, Cecchin G, Hoffman L, Penn P. A terapia familiar sistêmica de Milão.

Conversações sobre teoria e prática. Porto Alegre: Artes Médicas; 1993.

9. Guimarães FL. "O problema é que esse garoto, desde pequeno..." Construções narrativas acerca do adolescente no contexto de terapia familiar [dissertação]. Brasília (DF): Instituto de Psicologia, Universidade de Brasília; 2001.

10. Vasconcellos MJE. Implicações do "Pensamento sistêmico novo-paradigmático": a questão da dicotomia "terapia familiar sistêmica"/ "terapia familiar narrativista". Nova Perspectiva Sistêmica 2004;13(24):7-13.

11. Cabié MC. Adolescência e ciclo familiar existencial. In: Gammer C, Cabié MC. Adolescência e crise familiar. Lisboa: Climepsi; 1999.

12. Sudbrack MFO. O enfoque sistêmico aplicado à delinquiência e ao contexto jurídico. Família -
Temas de Terapia Familiar e Ciências Sociais 1992;5(1):29-42.

13. Bucher JSNF. Lei, transgressões, famílias e instituições: elementos para uma reflexão sistêmica. Psicologia: Teoria e Pesquisa 1992; 8(suplemento):475-83.

14. Ausloos G. Adolescence, délinquence et famille. Annales de Vaucresson 1997;14: 80-87.

15. Olivenstein C. A clínica do toxicômano: a falta da falta. Porto Alegre: Artes Médicas; 1985.

16. Sudbrack MFO. Da falta do pai à busca da lei: o significado da passagem ao ato delinqüente no contexto familiar e institucional. Psicologia: Teoria e Pesquisa 1992; 8(suplemento):447-57.

17. Penso MA. Dinâmicas familiares e construções identitárias de adolescentes envolvidos em atos infracionais e com drogas [tese]. Brasília (DF): Universidade de Brasília; 2003.

18. Schnitman DS, Fuks S. Paradigma y crisis: entre el riesgo y la posibilidad. Sistemas Familiares 1993; 9(3): 33-44.

19. Carter B, MacGoldrick M, organizadores. As mudanças no ciclo de vida familiar - uma estrutura para a terapia familiar. Porto Alegre: Artes Médicas; 1995.

20. Neuburger R. L'autre demande. Psychanalyse et thérapie familiale systémique. Paris: ESF ; 1984.

21. Gergen KJ. La construcción social: emergencia y potencial. In: Pakman M, organizador.

Construcciones de la experiencia humana. Vol.1, Barcelona: Editorial Gedisa; 1996.

22. Marcelli D, Braconnier A. Manual de psicopatologia do adolescente. Porto Alegre: Artes Médicas; 1989.

23. Ausloos G. A competência das famílias: tempo, caos, processo. Lisboa: Climepsi; 1996.

24. Omer H. Intervenções críticas em psicoterapia: do impasse ao início da mudança. Porto Alegre: Artes Médicas; 1997. 
25. Dabas EN. A intervenção em rede. Nova Perspectiva Sistêmica 1995; 6: 3-18.

26. Andersen T. Processos reflexivos. Rio de Janeiro: Noos; 1996.

27. Anderson H, Goolishian H. O cliente é o especialista. uma abordagem para terapia a partir de uma posição de não saber. Nova Perspectiva Sistêmica 1993; 2(3): 8-23.
28. Molina Loza CA. Chaves para uma terapêutica da família. Conhecer e compreender a família brasileira. Belo Horizonte: Artesã; 1998.

29. Moreno JL. Psicodrama. São Paulo: Cultrix; 1972.

30. Leveton E. Psicodrama para o clínico tímido. São Paulo: Manole; 1979.

31. Morin E. Introdução ao pensamento complexo. Lisboa: Instituto Piaget; 1991.

Recebido em: 24/03/2007 Modificado em: 23/05/2007 Aprovado em: 25/05/2007 